\title{
Eight-and-a-half Syndrome-A Rare Pontine Neuro-ophthalmological Syndrome
}

\author{
Kamatchi Sundaramoorthy ${ }^{1}$, Murali Kamalakannan², Swamy Kondapalli ${ }^{3}$, Sakthivelayutham Saravanan ${ }^{4}$, Sowmini Padmaja
} Raman $^{5}$, Malcolm Jeyaraj Krishnamoorthy ${ }^{6}$, Sathish Kumar Mallikarjuna7, Viveka Saravanan Raju ${ }^{8}$, Mugundhan Krishnan ${ }^{9}$

\begin{abstract}
The combination of one-and-a-half syndrome and facial nerve palsy is a rare neurological syndrome called eight-and-a-half syndrome, described first by Eggenberger in 1998. The one-and-a-half syndrome is characterized by ipsilateral conjugate horizontal gaze palsy (the "one") and an ipsilateral internuclear ophthalmoplegia (the "one-half"). A single unilateral lesion involving the paramedian pontine reticular formation or the abducens nucleus (causing the conjugate gaze palsy) with the interruption of internuclear fibers of the ipsilateral medial longitudinal fasciculus along with the region of facial colliculus results in eight-and-a-half syndrome. The occlusion of perforating artery to the pons resulting in pontine infarction is the commonest cause of this syndrome. The rare causes include demyelination, tumor, infection, and brainstem vasculitis. We describe here a case of eight-and-a half syndrome in a 50-year old gentleman due to pontine infarct, who also had cerebrovascular disease risk factors. Keywords: Eight-and-half syndrome, Internuclear ophthalmoplegia, Paramedian pontine reticular formation.

Bengal Physician Journal (2021): 10.5005/jp-journals-10070-7062
\end{abstract}

\section{INTRODUCTION}

Eight-and-a-half syndrome is a rare syndrome comprising of one-and-half syndrome with peripheral seventh nerve palsy. It is most often caused by a vascular etiology. It was first described in detail by Eggenberger ${ }^{1,2}$ in patients with the vertebro basilar disease as etiology in 1998. So far, 27 cases have been published. It is also described in multiple sclerosis by Skaat and Huna-Baron ${ }^{3}$ and Mortzos et al., ${ }^{4}$ rarely by space-occupying lesions, such as tuberculomas published by Vantoorn et al. ${ }^{5}$ Vascular etiology is the most common etiology in old age, whereas tumor, demyelination, and viral infections were found to be the common etiology in children. ${ }^{6}$

\section{Case Description}

A 50-year old male, right-handed, nonsmoker, and nonalcoholic, known case of systemic hypertension since 5 years and ischemic heart disease since 2 years on regular medications presented
${ }^{1-9}$ Department of Neurology, Stanley Medical College, Chennai, India Corresponding Author: Mugundhan Krishnan, Department of Neurology, Stanley Medical College, Chennai, India, Phone: +91 9844404280, e-mail: mugundhan69@gmail.com

How to cite this article: Sundaramoorthy $K$, Kamalakannan $M$, Kondapalli S, et al. Eight-and-a-half Syndrome-A Rare Pontine Neuroophthalmological Syndrome. Bengal Physician Journal 2021;8(3):81-83.

Source of support: Nil

Conflict of interest: None

with a sudden onset of giddiness followed by double vision on seeing more to his right side with slurring of speech and angle of the mouth deviation to the right, with no history suggestive of weakness, sensory disturbances, clumsiness, unsteadiness, headache, neck pain, previous cerebrovascular accidents, or tuberculosis. On examination, he had right eye exotropia, on
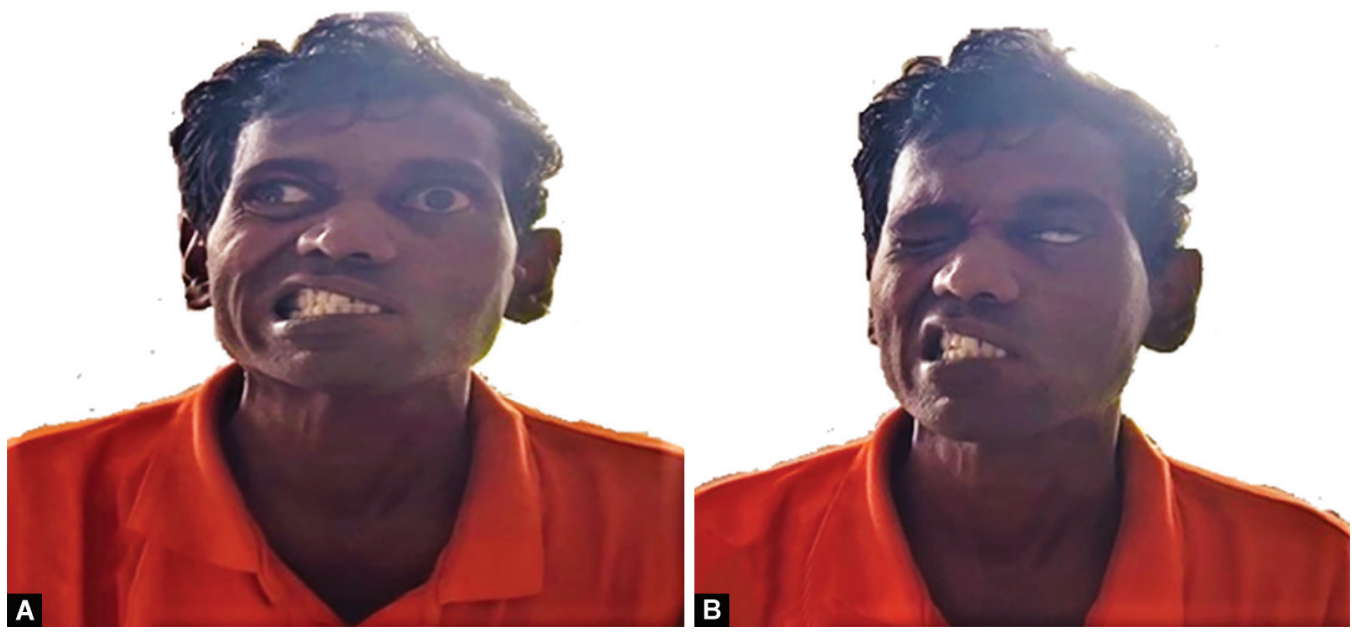

Figs $1 \mathrm{~A}$ and B: (A) Left LMN facial palsy; (B) Left Bell's phenomenon

() The Author(s). 2021 Open Access This article is distributed under the terms of the Creative Commons Attribution 4.0 International License (https://creativecommons. org/licenses/by-nc/4.0/), which permits unrestricted use, distribution, and non-commercial reproduction in any medium, provided you give appropriate credit to the original author(s) and the source, provide a link to the Creative Commons license, and indicate if changes were made. The Creative Commons Public Domain Dedication waiver (http://creativecommons.org/publicdomain/zero/1.0/) applies to the data made available in this article, unless otherwise stated. 

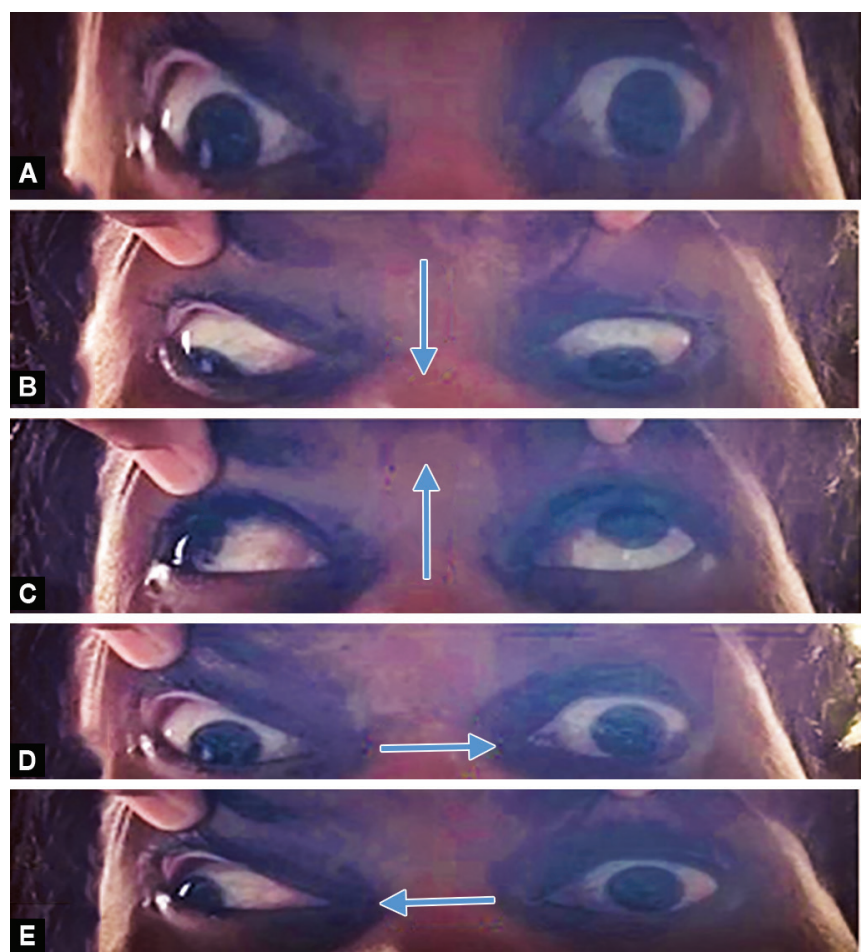

Figs 2A to E: (A) Primary gaze; (B) Looking down; (C) Looking up; (D) Looking left; and (E) Looking right
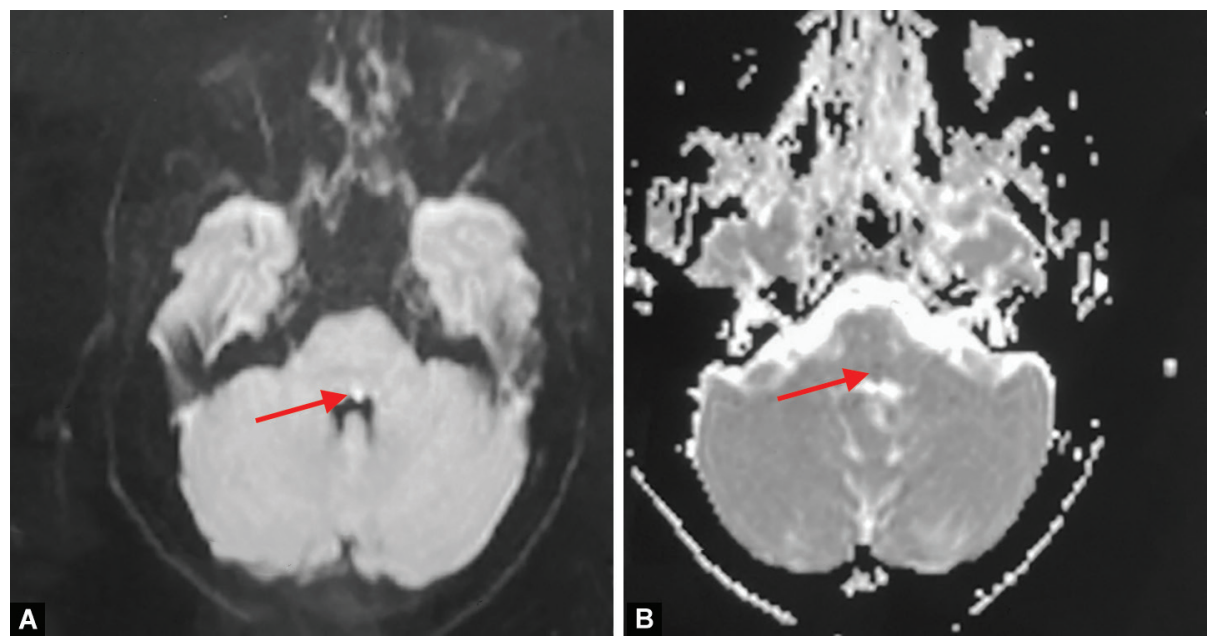

Figs $3 A$ and $B$ : MRI brain with (A) Diffusion restriction at left para pontine region ventral to fourth ventricle with; (B) Corresponding low ADC

looking to the left, there was left horizontal gaze palsy with absent left gaze saccades, on looking to the right, there was nystagmus in the right eye and the only movement intact was right eye abduction. Normal vertical gaze and saccades, with no impairment of vestibuloocular reflex. He also had left lower motor neuron facial palsy with bell's phenomenon. There was no ptosis, anisocoria other cranial nerve involvement, pyramidal, sensory, cerebellar, or meningeal involvement. MRI brain showed acute infarct with diffusion restriction in the caudal left parapontine region, ventral to the fourth ventricle. MRA was normal. Four-vessel Doppler revealed a mild increase in intimal thickness in both the vertebral arteries. An echocardiogram showed a normal left ventricular function. The patient was initiated on dual antiplatelets and high-dose statins. There was a mild improvement of adduction in the left eye, later discharged with medications and on regular follow-up (Figs 1 to 3 ).

\section{Discussion}

Eight-and-a-half syndrome is a combination of either ipsilateral seventh, sixth, and medial longitudinal fasciculus or ipsilateral seventh, ipsilateral parapontine reticular formation, and ipsilateral medial longitudinal fasciculus. ${ }^{7}$ This results in complete ipsilateral horizontal gaze palsy and contralateral 
partial gaze palsy with the seventh nerve palsy. Herring's law of equal innervation is the reason for contralateral eye abducting nystagmus. ${ }^{8}$ So far, 27 cases have been published, among those 18 were due to vascular, 4 were due to autoimmune, 3 were due to hemorrhagic stroke, and 1 was due to giant cell arteritis and pontine tuberculoma. ${ }^{9,10}$ Rarely, trigeminal neuralgia with eightand-a-half syndrome has been described. ${ }^{11}$ Commonly, facial palsy improves first followed by ocular symptoms. ${ }^{10}$ In vascular etiology, recovery is incomplete. ${ }^{10}$ The most common variant of one-and-a-half syndrome is eight-and-a-half syndrome. The occlusion of paramedian perforating artery to the pons results in lower pontine tegmentum infarction. ${ }^{11,12}$ In the cases described first by Eggenberger, lesions were not identified in MRI brain images. But later, Nandhagopal and Krishnamoorthy ${ }^{13}$ noted the MRI brain lesions at the lower pontine tegmentum, the presumed site of involvement by Eggenberger. The rare causes include demyelination, tumor, infection, and brainstem vasculitis. Mesina et al. ${ }^{14}$ described this syndrome in a 56-year old male who had pontine cavernoma.

\section{Conclusion}

This case report serves to emphasize the need for a high index of suspicion to diagnose this rare treatable neuro ophthalmologic syndrome.

\section{References}

1. Eggenberger E. Eight-and-a-half Syndrome. Journal of NeuroOphthalmology [Internet]. Ovid Technologies (Wolters Kluwer Health); 1998 Jun;18(2):114-116. Available from: http://dx.doi. org/10.1097/00041327-199806000-00008

2. Singh S, Sugantharaj V, Kumar MR, et al. A Rare Case of Eight-anda-half Syndrome: A Case Report. 2021;4(3):71-73. DOI: 10.5005/ jp-journals-10082-03122

3. Skaat A, Huna-Baron R. Eight-and-a-half syndrome: a rare neuroophthalmologic syndrome. Arch Neurol 2012;69(7):934-935. DOI: 10.1001/archneurol.2011.2185.
4. Mortoz $P$, Nordling MM, Sorensen TL. Eight-and-a-half syndrome as presenting sign of childhood multiple sclerosis. J AAPOS 2014;18(5):490-492. DOI: 10.1016/j.jaapos.2014.05.007.

5. Van Toorn R, Schoeman JF, Donald PR. Brainstem tuberculoma presenting as eight-and-a-half syndrome. Eur J Paediatr Neurol 2006;10(1):41-44. DOI: 10.1016/j.ejpn.2005.11.003.

6. Bodur M, Toker RT, Özmen AH, Okan MS. Facial colliculus syndrome due to a Herpes simplex virus infection following Herpes labialis. Turk J Pediatr. 2021;63(4):727-730. DOI: 10.24953/turkjped.2021.04.023. PMID: 34449158.

7. Kakar P, Brown Z, Banerjee S. Eight-and-a-half syndrome: an unusual presentation of brainstem infarction. QJM [Internet]. Oxford University Press (OUP); 2011 Oct 19;106(3):273-6. Available from: http://dx.doi.org/10.1093/qjmed/hcr187

8. Sandeep Reddy Nareddy, E.A. Ashok Kumar. A rare case of eight and a half syndrome due to pontine hemorrhage - A case report. IAIM, 2020;7(7):42-48. Available from: http://iaimjournal.com/

9. Jens W, Ahmed A (2015) Eight and a Half Syndrome from Multiple Sclerosis. J Neurol Stroke 3(4):00099. DOI: 10.15406/ jnsk.2015.03.00099.

10. Costa e Silva M, Mota C, Silva E, Barroso A. Eight-and-a-half Syndrome as The First Presentation of Unknown Metastatic Primary Tumor. Am J Biomed Sci \& Res 2021;13(6). AJBSR.MS.ID.001925. DOI: 10.34297/ AJBSR.2021.13.001925.

11. Koçer A. Eight-and-a-Half Syndrome Presented with Trigeminal Neuralgia. Annals of Case Reports and Images [Internet]. SciTeMed Publishing Group; 2018;1(2). Available from: http://dx.doi. org/10.24983/scitemed.acri.2018.00088

12. Xue, F, Zhang, L., Zhang, L., et al. (2017). One-and-a-half syndrome with its spectrum disorders. Quantitative imaging in medicine and surgery, 7(6):691-697. Available from: https://doi.org/10.21037/qims. 2017.12.04

13. Nandhagopal R, Krishnamoorthy SG. Neurological picture. Eightand-a-half syndrome. J Neurol Neurosurg Psychiatry 2006;77(4):463. DOI: 10.1136/jnnp.2005.078915.

14. Mesina BVQ, Sosuan GMN, Reyes KB. Eight-and-a-half syndrome: a rare potentially life-threatening disease. GMS Ophthalmol Cases 2018;8(8):Doc04. DOI: 10.3205/oc000086. PMID: 29977730; PMCID: PMC6008505. 